known about how the horse was domesticated (surprisingly little). Juliet CluttonBrock contributes an uplifting chapter on the horse in history, reminding us how important horses have been. Without the horse, Alexander the Great and Genghis Khan would probably not have been so successful, and the Spaniards could not have destroyed the Incas. The Roman Empire also depended largely on horses. Perhaps, she suggests, without raiding armies on horseback, many ancient civilizations would still be flourishing. At the very least, human history would have been different without the horse to accelerate the movement of people and their cultures and languages around the world.

The choice of subjects for the book, while interesting, does seem a little arbitrary. Why include a section on advanced techniques in horse medicine that have existed for only a short time, for example, but say very little about the animal's behaviour, which has been around for much longer?

Perhaps I am asking too much of books that both set out to describe the long history of human interaction with the horse and would not, despite their respective claims, have space to be truly comprehensive. But I could not help feeling disappointed that, although both described horses and their relationship to us in a fascinating way, neither addressed what is probably the hottest topic of all: the ethics of that relationship and what we do to horses.

Marian Stamp Dawkins is in the Department of Zoology, University of Oxford, South Parks Road, Oxford OX1 3PS, UK.

\section{A plague of weapons}

\section{The Eleventh Plague: The Politics of Biological and Chemical Warfare}

by Leonard A. Cole

W.H. Freeman: 1996. Pp. 284. \$22.95, £24.95

Alastair Hay

Leonard Cole ranks chemical and biological warfare as the "eleventh plague". The first ten, described in the book of Exodus, were reputedly inflicted by God on the Egyptians for their failure to release the Jews from slavery. The arsenal available to the Almighty would appear to have been more limited than it is now for, say, the United States or Iraq. Today, the ubiquity of the chemical industry and the widespread use of fermentation processes offer endless opportunities for synthesizing chemicals in bulk or culturing pathogenic organisms.

If the technology is no barrier to producing agents of chemical and biological warfare, what are the constraints on their use? This is the principal question addressed by Cole in

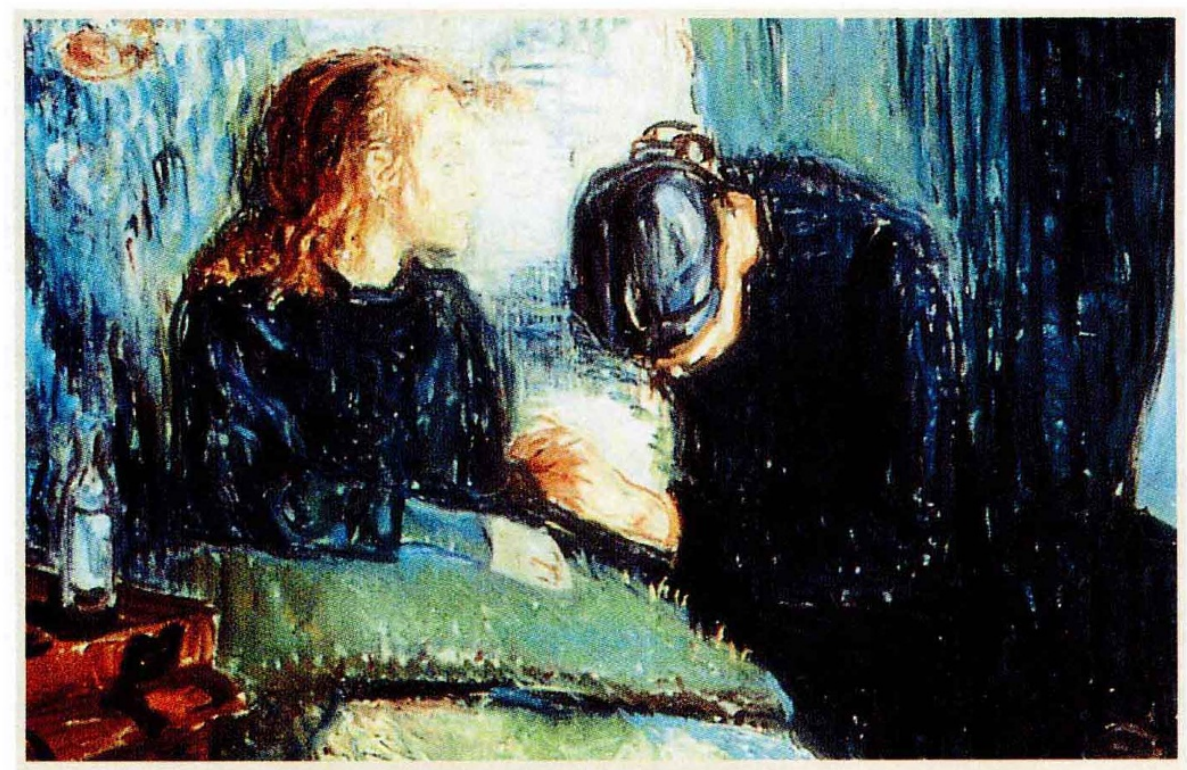

\title{
Art transplant
}

The surgeon Sir Roy Calne performed the first liver transplant in Europe. But he is an artist too, and has painted transplant patients and fellow surgeons. Many of these paintings are reproduced in his book Art, Surgery and

this critical, well researched and eminently readable book. After reviewing the strengths and weaknesses of the various treaties proscribing chemical and biological warfare deterrence and the huge costs required to maintain an adequate defence programme - Cole concludes, perhaps unsurprisingly, that a range of factors are required to deter use. These include verifiable treaties that allow inspections; defence programmes (justifiable both in cost and to the public they are meant to protect); good intelligence; and a much more outspoken position on the immorality of these weapons.

Three treaties prohibit the use of agents of chemical and biological warfare. Two of these, the 1925 Geneva Protocol and the 1972 Biological Weapons Convention, have no policing provisions and no sanctions. Apart from the exhortation to forswear the use of these agents, the treaties can do no more than create a climate hostile to their use. Cole points out that Iraq, even though a party to both treaties, developed a significant chemical and biological warfare capability, with the result that thousands of Iranians and Kurds were killed by Iraqi mustard and nerve gases.

This legacy has resulted in policing and inspection becoming two of the cornerstones of the 1993 Chemical Weapons Convention, which will become binding international law later this year. Many view it as the key to controlling chemical warfare, but two of the key signatories have still not ratified the treaty in their own parliaments and so are not bound byits provisions. The United States, which has more than 30,000 tonnes of chemical warfare
Transplantation (William \& Wilkins Europe, $£ 45$ ), along with other paintings about medicine by better-known artists. One such is The Sick Child by Edvard Munch (shown here), which hangs in the Tate Gallery in London.

agents, and Russia, which has nearly 40,000 tonnes, are still outside the fold. Both countries were major participants in all the negotiations that led to the treaty; it is embarrassing for both, and very disquieting for everybody else, that they are not signed-up members.

The control of biological weapons will be influenced by the success of the convention. There is no doubt that a policing system is urgently required for biological warfare agents. As for a defence programme on biological warfare, Cole observes that, in the United States, "hundreds of millions of dollars have been spent" on it, and yet, in his opinion, the "US citizenry is no better protected from a biological attack now than when the army's research program began half a century ago". Cole believes any future improvements in defence will be only marginal.

Vast resources have been spent building chemical arsenals; far more will be required to dismantle them. Research on biological warfare agents has been less costly but significant in the United States, the former Soviet Union and Iraq. Information about activities in other countries is more scanty.

There is still time to rein in these activities and to persuade countries that their security is enhanced by being party to treaties that prohibit chemical and biological warfare. In agreeing to abide by these treaties, countries are also taking the moral high ground. Chemical and biological warfare is immoral, and there are many who would class it in the way Cole does, as a disease.

Alastair Hay is in the School of Medicine,

University of Leeds, Leeds LS2 9JT, UK. 